Supporting information for

\title{
Efficient Formation of Site-specific Protein-DNA Hybrids using Copper-free Click Chemistry
}

\author{
Ann Mukhortava* ${ }^{\dagger}$ and Michael Schlierf*广 \\ ${ }^{\dagger}$ B CUBE - Center for Molecular Bioengineering, TU Dresden, Arnoldstr. 18, 01307 Dresden \\ *ann.mukhortava@bcube-dresden.de,schlierf@bcube-dresden.de
}

\section{Table of Contents}

Detailed protocol for the two-steps linking of oligos to proteins using DBCO-maleimide (DBCO-Mal) .......... 2

Detailed protocol for the one-step linking of maleimide-oligos to proteins ................................................. 3

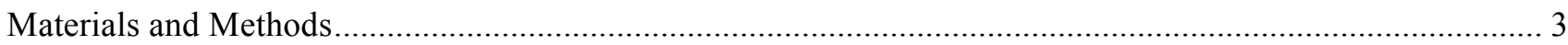

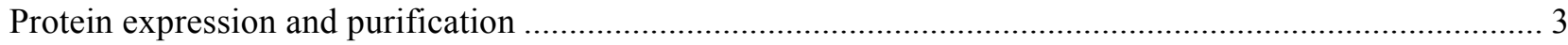

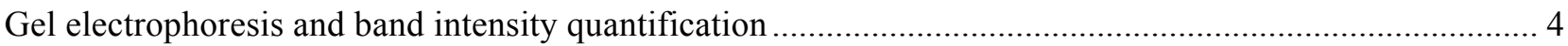

Protein-DNA construct formation for force spectroscopy measurement ….................................................. 4

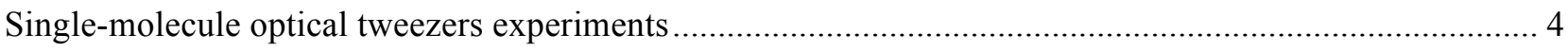

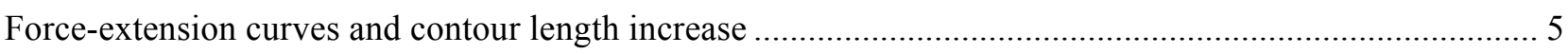

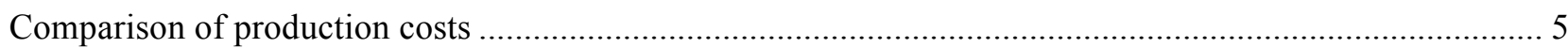

Table S1. Sequence of oligonucleotides used for protein coupling and PCR for DNA handle generation..... 6

Figure S1. Structure of the bifunctional maleimide-DBCO cross-linking reagent...................................... 7

Figure S2. Schematic representation of the click chemistry coupling reaction and the purification steps in

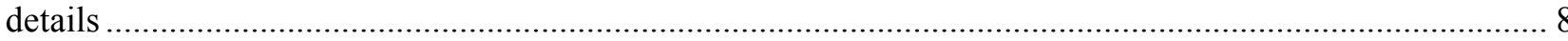

Figure S3. Schematic representation of the coupling reaction with maleimide-oligos and the purification steps in details

Figure S4. The comparison of the reaction efficiency of one step conjugation with 10-fold molar excess of maleimide-oligos and two step click chemistry based strategy

Figure S5. Typical FECs of U $\lambda U$ generated with the direct malemide-oligo conjugates (red trace) and with the click chemistry-based protein-DNA hybrids (black trace) …............................................................... 11

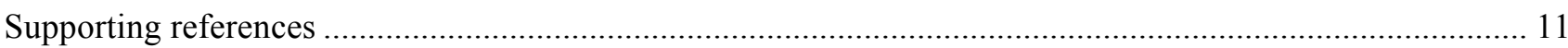




\section{Detailed protocol for the two-steps linking of oligos to proteins using DBCO- maleimide (DBCO-Mal)}

\section{Activation of protein cysteines with DBCO-Mal}

a) Reduce the protein of interest with at least 10-fold molar excess of TCEP per cysteine residue in a phosphate buffer (100 mM sodium phosphate buffer, $150 \mathrm{mM} \mathrm{NaCl}, \mathrm{pH} 7.0)$ for at least $30 \mathrm{~min}$ at RT.

b) It is important to maintain the buffer $\mathrm{pH}$ in a range of 6.5-7.5 to keep the maleimide group predominantly reacting to free sulfhydryls.

c) Freshly prepare in DMSO $20 \mathrm{mM}$ DBCO-Mal stock (Jena Biosciences).

d) Add DBCO-Mal in the 4-fold molar excess per reactive thiol-group in the tube with the reduced protein. Mix carefully. The final concentration of DMSO in the solution should not exceed 10\%.

e) Incubate the reaction for $2 \mathrm{~h}$ at $4^{\circ} \mathrm{C}$, pipetting up and down occasionally (incubation at room temperature is also possible. Recommended incubation time at RT is at least $1 \mathrm{~h}$ ).

f) Purify protein-DBCO solution from unreacted free DBCO-Mal and TCEP using a desalting column (e.g. PD SpinTrap ${ }^{\mathrm{TM}}$ G-25 column, GE Healthcare) following the provided protocol. Equilibration buffer should be $100 \mathrm{mM}$ sodium phosphate buffer, $150 \mathrm{mM} \mathrm{NaCl}, \mathrm{pH}$ 7.0. Final sample volume was $140 \mu \mathrm{l}$ (minimal working volume for the PD SpinTrap column).

\section{Click-coupling of the DBCO-activated protein to azide-oligos}

The limiting reagent for this reaction is the azide-oligomer (stock concentration: $1 \mathrm{nmol} / \mu \mathrm{l}$ in $100 \mathrm{mM}$ sodium phosphate buffer, $150 \mathrm{mM} \mathrm{NaCl}, \mathrm{pH}$ 7.0)

a) Mix $0.5 \mathrm{nmol}$ DBCO-activated protein with $2.5 \mathrm{nmol}$ azide-oligos (2.5-fold molar excess per reactive cysteine residue). Typical final reaction volume was $20 \mu 1$.

b) Incubate the reaction at $4^{\circ} \mathrm{C}$ for $6 \mathrm{hrs}$.

c) Purify the mixture from unreacted oligos with His SpinTrap ${ }^{\mathrm{TM}}$ column, GE Healthcare following the provided protocol. Binding buffer was $50 \mathrm{mM}$ Tris- $\mathrm{HCl}, 300 \mathrm{mM} \mathrm{NaCl}, 20 \mathrm{mM}$ Imidazole, pH 8.0; elution buffer was $50 \mathrm{mM}$ Tris- $\mathrm{HCl}, 300 \mathrm{mM} \mathrm{NaCl}, 500 \mathrm{mM}$ Imidazole, $\mathrm{pH}$ 8.0. Final sample volume was $400 \mu \mathrm{l}$ ( 2 elution steps). 
d) If desired, concentrate protein-oligo sample with Vivaspin ${ }^{\mathrm{TM}} 500$ columns (GE Healthcare). Here, we concentrated the sample 10 -fold to a final volume of $40 \mu \mathrm{l}$.

\section{Detailed protocol for the one-step linking of maleimide-oligos to proteins}

a) Reduce of the protein of interest with at least 10-fold excess of TCEP for cysteines amount in a phosphate buffer with TCEP (100 mM sodium phosphate buffer, $150 \mathrm{mM} \mathrm{NaCl}, \mathrm{pH} 7.0$, $2 \mathrm{mM}$ TCEP, $\mathrm{pH}$ 7.0) for at least $30 \mathrm{~min}$ at RT.

b) It is important to maintain the buffer $\mathrm{pH}$ in a range of 6.5-7.5 to keep the maleimide group predominantly reacting to free sulfhydryls.

c) Dissolve maleimide oligos in $100 \mathrm{mM}$ sodium phosphate buffer, $150 \mathrm{mM} \mathrm{NaCl}$, pH 7.0 (e.g. make a stock: $0.5 \mathrm{nmol} / \mu \mathrm{l})$.

d) Mix protein with maleimide-oligo in a 1:8 ratio (here $0.5 \mathrm{nmol}$ protein was added to $4 \mathrm{nmol}$ maleimide-oligo). Keep the reaction volume small, about $20 \mu 1$.

e) Incubate the reaction at $4^{\circ} \mathrm{C}$ overnight $(\sim 12 \mathrm{hrs})$.

f) Purify the mixture from unreacted oligos with His SpinTrap ${ }^{\mathrm{TM}}$ column, GE Healthcare following their standard protocol. Binding buffer - $50 \mathrm{mM}$ Tris- $\mathrm{HCl}, 300 \mathrm{mM} \mathrm{NaCl}, 20 \mathrm{mM}$ Imidazole, $\mathrm{pH}$ 8.0; elution buffer - $50 \mathrm{mM}$ Tris- $\mathrm{HCl}, 300 \mathrm{mM} \mathrm{NaCl}, 500 \mathrm{mM}$ Imidazole $\mathrm{pH}$ 8.0. Final sample volume $-400 \mu \mathrm{l}$ ( 2 elution steps).

g) If desired, concentrate protein-oligo sample 10x times with Vivaspin ${ }^{\mathrm{TM}} 500$ columns, GE Healthcare to a final volume of around $40 \mu \mathrm{l}$.

\section{Materials and Methods}

\section{Protein expression and purification}

Lambda repressor fragment Lambda ${ }_{6-85}\left(\lambda_{6-85}\right)^{1}$ was cloned into the pET28a expression plasmid between two ubiquitins $(\mathrm{U})$ with terminal cysteines ${ }^{2}$. The protein construct was expressed in E. coli $\mathrm{BL} 21(\mathrm{DE} 3)$ at $37^{\circ} \mathrm{C}$ for $3 \mathrm{hrs}$ after induction with IPTG at $\mathrm{OD}_{600} \approx 0.8$. Harvested cells were resuspended in buffer (50 mM Tris- $\mathrm{HCl}, \mathrm{pH} 8.0,300 \mathrm{mM} \mathrm{NaCl}, 20 \mathrm{mM}$ Imidazole) and lysed with EmulsiFlex-C5 (Avestin). The supernatant was filtered and applied to a $1 \mathrm{~mL}$ Ni-NTA Sepharose ${ }^{\circledR}$ column (GE Healthcare). Protein construct U $\lambda U$ was eluted by a step-wise increase of Imidazole concentration (40-500 mM). 
The full length protein construct sequence is shown below, where $\lambda_{6-85}$ is underlined:

MACKMQIFVKTLTGKTITLEVEPSDTIENVKAKIQDKEGIPPDQQRLIFAGKQLEDGRTLSDY NIQKESTLHLVLRLRGGELSLTQEQLEDARRLKAIWEKKKNELGLSQESVADKMGMGQSG VGALFNGINALNAYNAALLAKILKVSVEEFSPSIAREIRGTMQIFVKTLTGKTITLEVEPSDTI ENVKAKIQDKEGIPPDQQRLIFAGKQLEDGRTLSDYNIQKESTLHLVLRLRGGKCLEHHHHH*.

\section{Gel electrophoresis and band intensity quantification}

Linear 12\% (29:1 acrylamide/bisacrylamide) SDS gels were used for PAGE. After the gel electrophoresis, the gels were stained with Coomassie blue and imaged in white illumination using a Stella 3200 system (Raytest). Subsequently, the gel was stained with SYBR ${ }^{\circledR}$ Gold (Invitrogen, Thermo Fisher Scientific) and imaged with fluorescence (UV-excitation) on the Stella 3200 system. $\mathrm{SYBR}^{\circledR}$ Gold fluorescence is shown in the figures as black (inverted signal) for better visibility. Unreacted oligos could not be visualized by SYBR ${ }^{\circledR}$ Gold staining, due to diffusion/migration of the oligo out of the gel. Band intensity analysis was performed with ImageJ software via determining a profile plot of each selected gel lane (see Figure S3, blue rectangles). Each peak was labelled with its area, expressed as a percentage of the total area of all peaks pertaining to the selected lane. Normalized this way, the obtained percentage values for protein-alone and the protein-DNA conjugates bands directly represent the efficiency of coupling reaction.

\section{Protein-DNA construct formation for force spectroscopy measurement}

For the attachment of oligos to protein, we used a DBCO-maleimide based protocol outlined below. Differently functionalized DNA linkers of $310 \mathrm{~nm}(913 \mathrm{bp})$ length each were generated by PCR with Phusion polymerase (Thermo Fisher Scientific) using a lambda-phage DNA template (Promega). The forward primers were either biotin or digoxigenin modified oligos. A reverse primer introduced an abasic site to leave a ssDNA 32 nucleotides overhang complementary to the protein-bound oligos ${ }^{2}$. A 2:1:1 mixture of the protein-oligo construct with the functionalized DNA handles resulted after 2 hrs of incubation in the final protein-DNA construct for single-molecule force spectroscopy.

\section{Single-molecule optical tweezers experiments}

Protein-DNA constructs were incubated with $2 \mu \mathrm{m}$ silica beads (Bangs Laboratories, Inc), which were previously covalently functionalized with anti-digoxigenin $\mathrm{F}_{\mathrm{ab}}$ fragments (Roche). The mixture was diluted in optical tweezers buffer (50 $\mathrm{mM}$ sodium phosphate buffer, $250 \mathrm{mM} \mathrm{NaCl}, 1 \%$ (w/v) D- 
glucose, $\mathrm{pH}$ 7.1) and mixed with streptavidin-coated $1 \mu \mathrm{m}$ silica beads (Bangs Laboratories, Inc.). Measurements were carried out at room temperature in optical tweezers buffer after addition of an oxygen scavenger system ( $26 \mathrm{U} / \mathrm{ml}$ glucose oxidase, $17000 \mathrm{U} / \mathrm{ml}$ catalase). Protein-DNA conjugates concentration was adjusted to only sparsely cover the beads leading mainly to single-tether formation. The beads were trapped in the foci of a dual trap optical tweezers platform (JPK NanoTracker ${ }^{\mathrm{TM}}$ ). $1 \mu \mathrm{m}$ and $2 \mu \mathrm{m}$ trapped beads were brought into close proximity (Figure 3A) for tether formation. The beads were then separated with a constant velocity yielding force vs. extension traces as shown in Figure 3B. The recorded stretch-and-relax cycles were analyzed afterwards. Trap stiffness was determined using a previously described calibration protocol ${ }^{3}$. The effective trap stiffness was determined with an error of $\sim 10 \%$ and varied from 0.056 to $0.062 \mathrm{pN} / \mathrm{nm}$. Data were acquired at a sampling rate of $50 \mathrm{kHz}$. The signals were corrected for cross talk.

\section{Force-extension curves and contour length increase}

The force-extension curves can be well described with polymer elasticity models. Before unfolding, the DNA elasticity was modeled with a worm-like chain model (WLC):

$$
F_{\mathrm{WLC}}(x)=\frac{k_{\mathrm{DNA}} T}{p_{\mathrm{DNA}}}\left(\frac{1}{4}\left(1-\frac{x}{L_{\mathrm{DNA}}}\right)^{-2}+\frac{x}{L_{\mathrm{DNA}}}-\frac{1}{4}\right)
$$

with the persistence length $p_{\mathrm{DNA}}$ and contour length $L_{\mathrm{DNA}}$ and extension $x$. DNA contour length was set to $620 \mathrm{~nm}$ and the fit yielded persistence lengths of $\sim 20-30 \mathrm{~nm}$. After unfolding of the protein, a combined worm-like chain model was used, modeling the peptide elasticity with:

$$
F_{\mathrm{WLC}_{\text {prot }}}(x)=\frac{k_{\mathrm{B}} T}{p_{\text {prot }}}\left(\frac{1}{4}\left(1-\frac{x}{L_{\text {prot }}}\right)^{-2}+\frac{x}{L_{\text {prot }}}-\frac{1}{4}\right),
$$

with persistence length $p_{\text {prot }}$ set to $0.5 \mathrm{~nm}^{2}$, contour length $L_{\text {prot }}$, and extension $x$. The contour length increase $\Delta L_{\text {prot }}$ was calculated from the WLC fits.

\section{Comparison of production costs}

The major contribution to the production costs of a protein-DNA hybrid is the cost for the modified oligo. Due to the challenging production, modification of oligos with maleimide groups is typically 2 times more expensive than azide-modified ones. Moreover, we showed that a 4-fold molar excess of maleimide oligos is required to get a detectable yield of protein-DNA hybrids compared to the needed amount of azide-functionalized oligos. Thus, the commonly used conjugation method with maleimideoligos appears to be at least 8 times more expensive than the proposed click chemistry method.

For conjugation of $1 \mathrm{nmol}$ protein with two attachment cysteine residues according to the commonly used approach 10-fold molar excess of maleimide-oligo per cysteine residue, resulting in $20 \mathrm{nmol}$ of 
maleimide-oligo required. Typically, $20 \mathrm{nmol}$ maleimide-oligo were obtained for approx. $160 €$ (biomers.net $\mathrm{GmbH}, 50 \mathrm{nmol}$ scale synthesis). In contrast, for the same initial protein amount to have the same conjugation yield, $8 \mathrm{nmol}$ of DBCO-maleimide cross linker and $5 \mathrm{nmol}$ azide-modified oligos have to be used. For the latter ones, typically $50 \mathrm{nmol}$ of synthesis product was obtained for approx. $90 €$ (biomers.net $\mathrm{GmbH}, 50 \mathrm{nmol}$ scale synthesis). Taking into account that the negligibly small costs of DBCO-maleimide for the given reaction $(0.02 € / 10 \mathrm{nmol}$, Jena Bioscience). The total cost of proposed two-step strategy was then around $9 €$ per 1 nmol protein in contrast to $160 €$ for the maleimide-oligo method.

Table S1. Sequence of oligonucleotides used for protein coupling and PCR for DNA handle generation

\begin{tabular}{|c|c|c|}
\hline Name (length) & Sequence & \\
\hline $\begin{array}{l}\text { Maleimide-oligo } \\
\text { (32 nt) }\end{array}$ & $\begin{array}{l}\text { 5'- } \\
\text { CGTTGTTGCTATTGGTAGGCGGTGACCCGT } \\
\text { CC-Mal-3' }\end{array}$ & \multirow[t]{2}{*}{$\begin{array}{l}\text { biomers.net } \\
\text { GmbH }\end{array}$} \\
\hline Azide-oligo (32 nt) & $\begin{array}{l}\text { 5'- } \\
\text { CGTTGTTGCTATTGGTAGGCGGTGACCCGT } \\
\text { CC-Azid-3' }\end{array}$ & \\
\hline $\begin{array}{l}\text { Bio-handle forward } \\
\text { primer }\end{array}$ & 5'-Bio-ATCCGCAGAAGACGCAGATGCC-3' & \multirow[t]{3}{*}{$\begin{array}{l}\text { Eurofins } \\
\text { Genomics }\end{array}$} \\
\hline $\begin{array}{l}\text { Dig-handle forward } \\
\text { primer }\end{array}$ & 5'-Dig-ATCCGCAGAAGACGCAGATGCC-3' & \\
\hline $\begin{array}{l}\text { Reverse primer } \\
\text { with an abasic site } \\
\text { (Z-position) }\end{array}$ & $\begin{array}{l}\text { 5'- } \\
\text { GGACGGGTCACCGCCTACCAATAGCAACA } \\
\text { ACGZTGCAGCAGGATCAGCCACGG-3' }\end{array}$ & \\
\hline
\end{tabular}




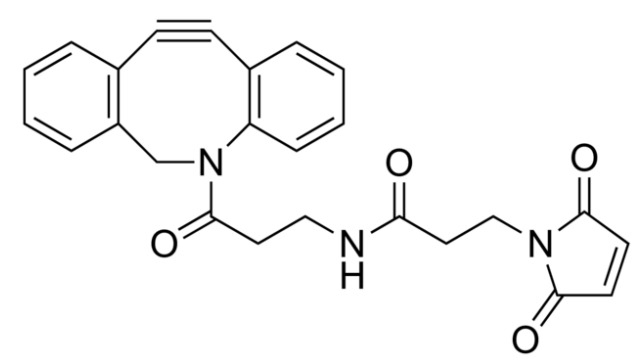

Figure S1. Structure of the bifunctional maleimide-DBCO cross-linking reagent 
Step 1: Activation of protein cysteines with DBCO-Mal

Reaction Mixture
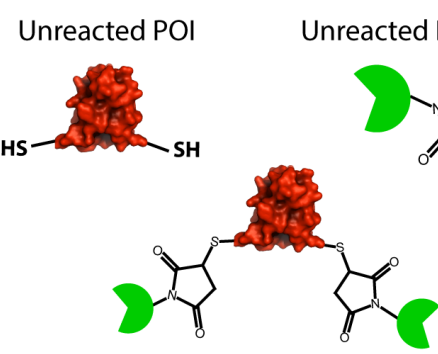

DBCO-activated POI
Desalting column

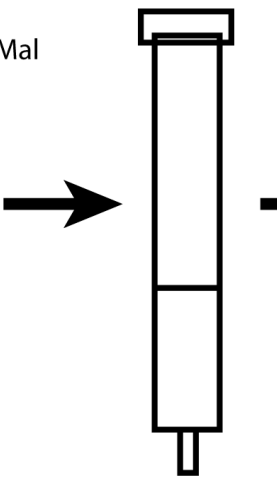

Elution

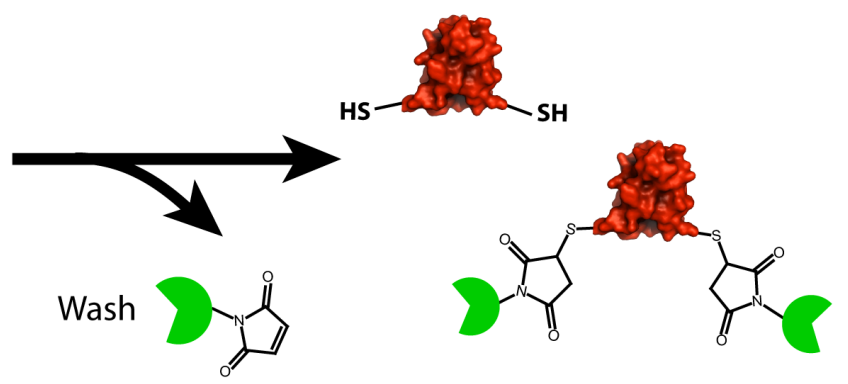

Step 2: Click-coupling of the DBCO-activated protein to azide-oligos

Reaction Mixture

Ni-column

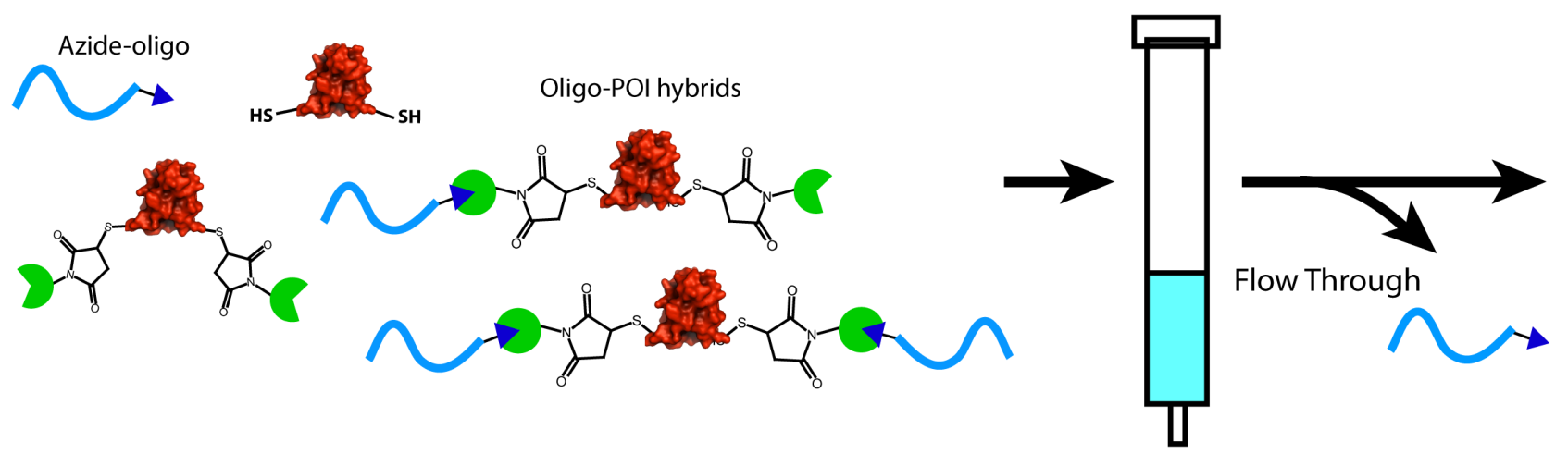

Imidazole Elution

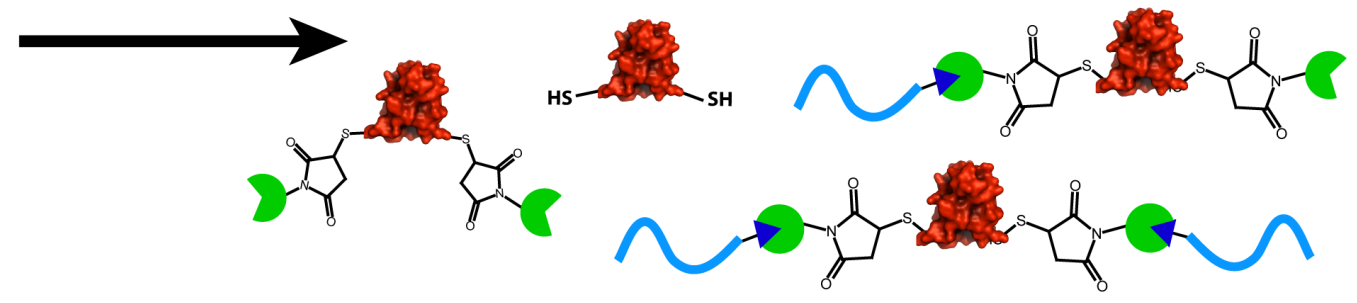

Figure S2. Schematic representation of the click chemistry coupling reaction and the purification steps in details 
Coupling of maleimide-oligos to protein (one step reaction)

Reaction Mixture
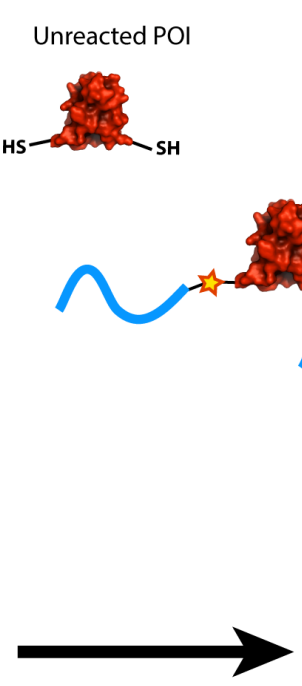

Maleimide-oligo

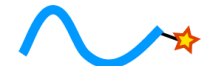

Oligo-POI hybrids

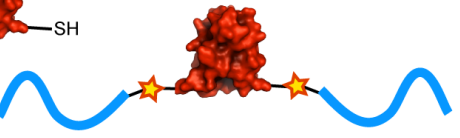

$\mathrm{Ni}$-column

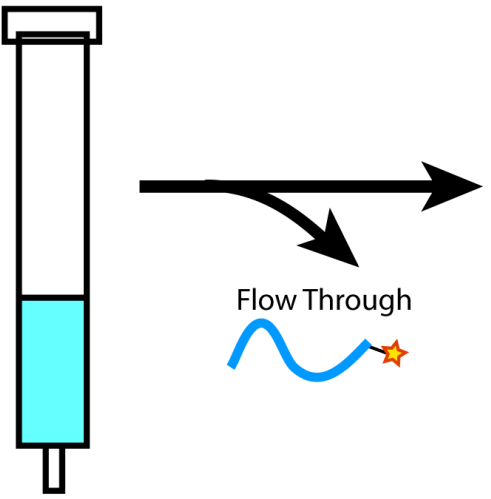

Imidazole Elution

Oligo-POI hybrids
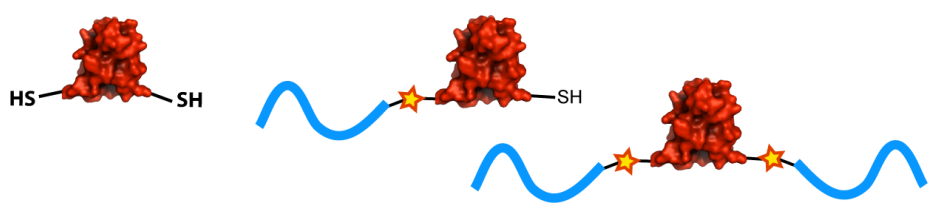

Figure S3. Schematic representation of the coupling reaction with maleimide-oligos and the purification steps in details 
a) Coomasie staining

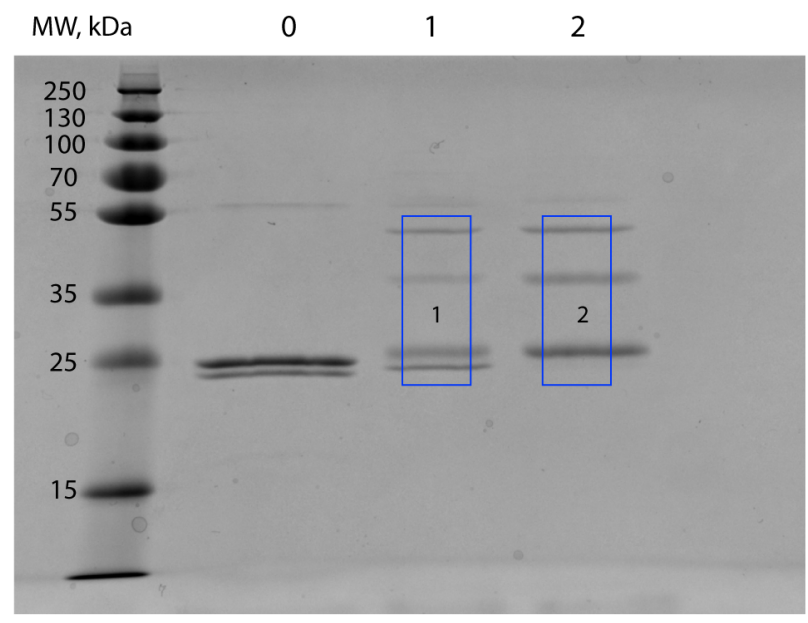

b)

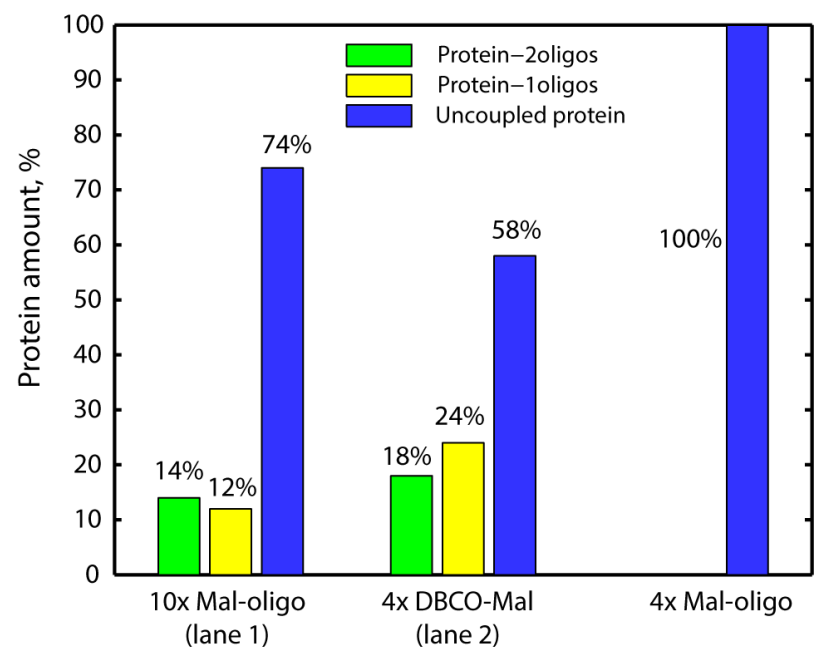

Figure S4. The comparison of the reaction efficiency of one step conjugation with 10-fold molar excess of maleimide-oligos and two step click chemistry based strategy

The 12\% SDS-PAGE gel was stained with Coomassie blue. A) Lane 0 - U $\lambda$ U protein construct alone, $28 \mathrm{kDa}$; lane 1 - products of the one step reaction of $U \lambda U$ with 10 -fold molar excess of maleimideoligos to cysteines; lane 2 - products of the click chemistry based coupling reaction. Blue rectangles highlight the band areas analyzed by ImageJ. B) Comparison of reaction efficiency of the three presented coupling methods. Each band intensity was quantified and expressed as a percentage of the total intensity of all bands pertaining to the selected lane. Normalized this way, the obtained percentage values for protein-alone and the protein-DNA conjugates bands directly represent the efficiency of coupling reaction. 


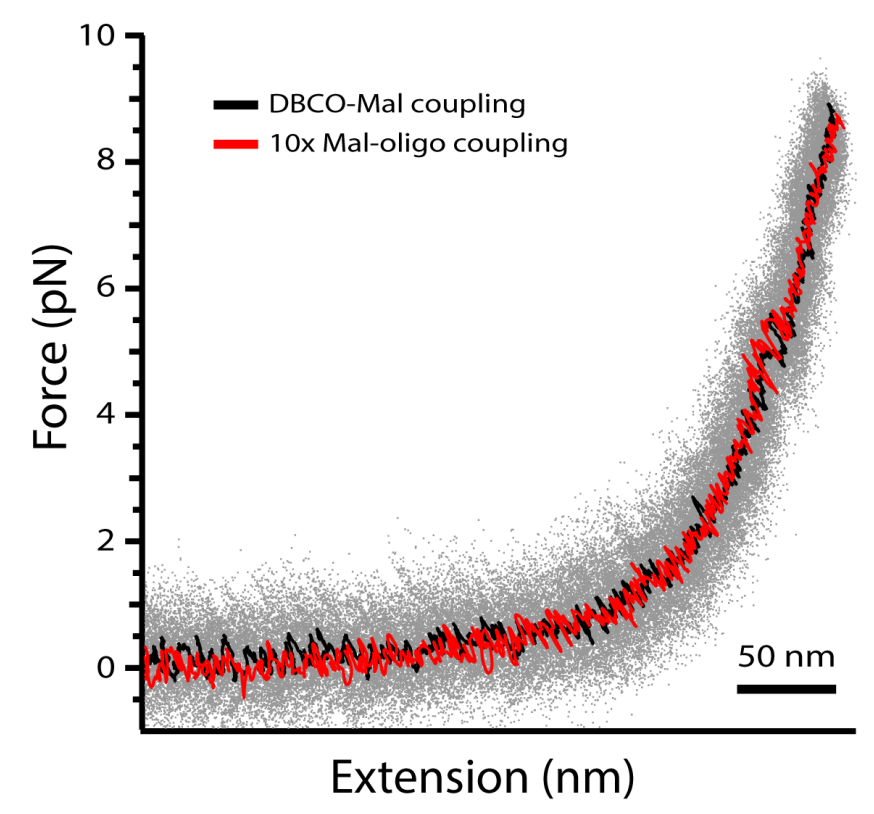

Figure S5. Typical FECs of UגU generated with the direct malemide-oligo conjugates (red trace) and with the click chemistry-based protein-DNA hybrids (black trace)

\section{Supporting references}

(1) Huang, G. S., and Oas, T. G. (1995) Structure and stability of monomeric lambda repressor: NMR evidence for two-state folding. Biochemistry 34, 3884-92.

(2) Stigler, J., Ziegler, F., Gieseke, A., Gebhardt, J. C. M., and Rief, M. (2011) The Complex Folding Network of Single Calmodulin Molecules. Science. 334, 512-516.

(3) Tolić-Norrelykke, S. F., Schäffer, E., Howard, J., Pavone, F. S., Jülicher, F., and Flyvbjerg, H. (2006) Calibration of optical tweezers with positional detection in the back focal plane. Rev. Sci. Instrum. 77, 103101. 